\title{
The Knowledge about the Dangerous Effect of Opiates among Adolescent
}

\author{
A.S. Ishak ${ }^{1, *}$, Hussin H. ${ }^{1}$, Alia Asrani Azmi ${ }^{1}$, and M.H. Othman ${ }^{2}$ \\ ${ }^{1}$ School of Human Development and Technocomunication (iKOM), Universiti Malaysia Perlis, Perlis, Malaysia \\ ${ }^{2}$ School of Education Studies, Universiti Sains Malaysia, Penang, Malaysia
}

\begin{abstract}
Statistics from the National Anti Drug Agency (AADK) showed an increase in adolescent who are in the age range 13 to 18 years involved in drug abuse. Realizing this problem, a study was conducted to examine the knowledge about dangerous effect of drug abuse on opiates among adolescent. There are four type of opiates were tested in this study such as opium, morphine, heroin and codeine. Respondent consisted 759 adolescent aged 16 years old. This quantitative study using the "Soal Selidik Kajian Pengaruh Dadah" as an instrument. The data obtained were analyzed using descriptive statistics to get the frequency and percentage. The result showed that both male and female adolescent know about the dangerous effect of drug abuse. Findings also identify the most popular drugs among adolescent is heroin followed by opium, codein and morphine.
\end{abstract}

\section{Introduction}

Drug abuse among adolescent has increased all over the world and the age of initiation of abuse is progressively falling. Encouragement from the peer group, deep desire to be popular, poor parental control and easy availability of the substances make an adolescent to go for drug abuse. Earlier initiation of drug use is found to have more impairment, crime, and difficult to quit and is usually associated with a poor prognosis and a lifelong pattern of deceit and irresponsible behaviour [1].

Knowledge about the age of drug abuse commence is of paramount in importance. There are a few studies has been associated with the knowledge about drug abuse. High knowledge of harmful effects of substance was reported in students [2-7], health professionals [8-9] and general public [10]. Several studies in adolescent population have reported positive association between knowledge about substance abuse and their attitudes toward substances [2-4]. Nahid et al, 2014 conduct the study and gathered data about the type of drug abused, knowledge about short term and long term complications of narcotics and stimulants.

\subsection{Objective of Study}

The present study was comprehensively assess the knowledge about the dangerous effect of drug abuse on opiates among adolescent. Adolescent is a critical time in one's life, and the habit and behaviour formed during this years can have a long lasting impact on the health of the individual. In Malaysia, opiates are the most commonly abused drug, followed closely by cannabis and amphetamine based stimulant, [11]. The table below shown the statistic of most commonly used addictive drug by Agensi Anti Dadah Kebangsaan, Malaysia (AADK) from 2010- 2015. 
Table 1. Statistic of Most Commonly Used Addictive Drug 2010-2015

\begin{tabular}{ccccccccc}
\hline Year & Opiate & Opium & Cannabis & $\begin{array}{c}\text { Metha- } \\
\text { phetamin }\end{array}$ & ATS & $\begin{array}{c}\text { Psikotropik } \\
\text { Pil }\end{array}$ & Others & Total \\
\hline 2010 & 11,664 & 31 & 3,011 & 4,026 & 4,525 & 94 & 291 & 23,642 \\
& $49.34 \%$ & $0.13 \%$ & $12.73 \%$ & $17.03 \%$ & $19.14 \%$ & $0.40 \%$ & $1.23 \%$ & $100 \%$ \\
\hline \multirow{2}{*}{2011} & 9,629 & 9 & 2,026 & 7,034 & 604 & 58 & 171 & 19,531 \\
& $49.30 \%$ & $0.05 \%$ & $10.37 \%$ & $36.01 \%$ & $3.09 \%$ & $0.30 \%$ & $0.88 \%$ & $100 \%$ \\
\hline \multirow{2}{*}{2012} & 8,472 & 9 & 1,427 & 4,761 & 286 & 66 & 80 & 15,101 \\
& $56.10 \%$ & $0.06 \%$ & $9.45 \%$ & $31.53 \%$ & $1.89 \%$ & $0.44 \%$ & $0.53 \%$ & $100 \%$ \\
\hline \multirow{2}{*}{2013} & 16,035 & 0 & 1,885 & 2,901 & 476 & 18 & 46 & 21,361 \\
& $75.07 \%$ & $0.00 \%$ & $8.82 \%$ & $13.58 \%$ & $2.23 \%$ & $0.08 \%$ & $0.22 \%$ & $100 \%$ \\
\hline \multirow{2}{*}{2014} & 14,496 & 0 & 1,919 & 4,117 & 1,774 & 6 & 43 & 22,355 \\
& $64.84 \%$ & $0.00 \%$ & $8.58 \%$ & $18.42 \%$ & $7.94 \%$ & $0.03 \%$ & 0.19 & $100 \%$ \\
\hline \multirow{2}{*}{2015} & 16,616 & 0 & 1,389 & 8,133 & 1,314 & 1 & 26 & 27,479 \\
& $60.48 \%$ & $0.00 \%$ & $5.05 \%$ & $29.60 \%$ & $4.78 \%$ & $0.00 \%$ & $0.09 \%$ & $100 \%$ \\
\hline
\end{tabular}

Table 1: Type of Drug

Source: Agensi Anti Dadah Kebangsaan, 2015

\subsection{Type of Opiates}

Drug are psychoactive chemical materials that's affect the central nerve system until a user is in a condition of intoxication, addiction and behavioral problems. Drug are chemical materials dangerous to individuals that partake in them, as it changed how the mind and body function. Drug are a special term referring to substances that harm a user's physical, mental and emotional health as well as behaviour after use. As a result, a drug abuser becomes addicted and is highly dependence on the substance [12]

An opiate is a narcotic analgesic that directly depresses the central nervous system." There are three types of opiates: natural, synthetic, and semisynthetic. While some of these drugs are used for medicinal purposes, others are illegal and highly dangerous. However, all opiates can become addictive when abused. Listed below are the most commonly used and abused opiate drugs. These substances occur naturally within the poppy plant. While they are often thought to be less harmful than synthetics, they can still become addictive and cause dangerous respiratory depression.

\subsubsection{Opium}

Opium serves to depress the central nervous system. Opium comes from the poppy seed that turns from a while to brown- blackish in hue. It has a strong odour, is elastic when new and hardens after expose to air. It is most commonly smoked and often combined with other drugs of abuse like marijuana and methamphetamine.

\subsubsection{Morphine}

Morphine is classified as an opiate drug and is primarily used for short and long-term pain relief. Like other opiate drugs, it is derived from the poppy plant and can also be categorized as a narcotic. Morphine is available in several forms, such as in a syrup, injection, tablet or suppository. Morphine can be injected or taken as a tablet, suppository, or capsule.

\subsubsection{Heroine}

Heroine is the name for a modified version of morphine that is very addictive and illegal opioid drug. The drug is available on the illicit market in a number of different varieties, with purer product tending to occur in white powder form. Heroin may be smoked, snorted, or injected. Regardless of the type of use, heroin acts quickly in the body to elicit its dramatic results. In short, heroin is very harmful. The speed and intense effects of the substance are main contributors to its harmful nature. They are also factors that lead to the addictive nature of heroin.

\subsubsection{Codein}

Codein is naturally-occurring alkaloid in opium. However, most codein in the market is produced 
from morphine. In the medical field, codein is used to alleviate mild pain and as cough medicine. Whether codein is used properly or it is abused, it has many of the same effects as other opiates. Codein may cause nausea, vomiting and drowsiness. Since opiates suppress breathing, the codeine may have slowed breathing or difficulty getting his breath. Codein is swallowed or injected and often abused as a cough syrup and mixed with soda and alcohol.

\section{Material and Methods}

\subsection{Research design}

This descriptive study using quantitative methods, namely through the use of set questionnaire. Refers to descriptive statistical methods to describe the characteristics of the the sample [13]. According to Mohd. Majid (1993), a questionnaire more practical and effective use because its use can improve the accuracy and correctness of responses given by the sample. This is because it is not affected by gestures researchers. They are free to express their own opinion to answer each item submitted.

\subsubsection{Participant}

Female and male adolescent aged 16 years old from three states from northern Peninsular of Malaysia (Perak, Pulau Pinang and Kedah) responded to the questionnaire.

\subsubsection{Procedure of Data Collection}

In this study, researchers used questionnaires to obtain research data. According to Mohd Majid (1994), a questionnaire was used because it is easier to get cooperation of respondents. The questionnaire can accommodate that many respondents to increase reliability study. The use of the questionnaire is simple and easily administered.
Suggestion of the answers will allow respondents to answer the question fast.

The "Soal Selidik Kajian Pengaruh Dadah" which consisted of 3 parts was used. Part A is related to the student demographics; gender, race and current living. Part B is a knowledge / experience regarding drugs. Six type of drug are tested in this study; opium, depresen, marijuana, heroin, codein, morphine, ecstasy, methaphetamin and cocaine.

Analysis was done by SPSS version 22.0. The data was presented in percentages and frequencies, from which the researcher presented it in table, figures and graph.

\section{Result}

After collecting all the questionnaire, only 759 were used for this study. There were more female $(\mathrm{n}=425 ; 56.0 \%)$ participant compared to males $(n=334 ; 44 \%)$. The majority of the respondents were Malay $(\mathrm{n}=691 ; 91.0 \%)$. Chinese respondents were $(n=6 ; 0.8 \%)$ while the Indians $(n=59 ; 7.8 \%)$. There are also respondents from other nations $(\mathrm{n}=$ $3 ; 0.4 \%)$. Most of the respondents living at home ( $\mathrm{n}$ $=671 ; 88.4 \%)$ than in the hostel $(\mathrm{n}=88 ; 11.6 \%)$. Some demographic characteristic of the participant are presented in Table 2. Table 2 shows the analysis of the dangerous effects of opiates drugs among adolescents. It was found that both male and female know about the dangerous effects of drugs. Generally its seem that female have a higher level of knowledge about the dangerous effects of opiates. This is because more female respondent than male. The male who know the dangerous effect of opium is $(n=104 ; 13.70 \%)$, morphine ( $n$ $=68 ; 9.0 \%)$, heroin $(n=147 ; 19.4 \%)$, and codeine $(\mathrm{n}=56 ; 7.4 \%)$. While the female who know the dangerous effects of opium is $(n=116 ; 15.3 \%)$, morphine $(n=84 ; 11.1 \%)$, heroin $(n=185 ; 24.4 \%)$ and codeine $(n=278 ; 36.6 \%)$.

Table 2. Demographic Background

\begin{tabular}{llll}
\hline Background & & Number & $\%$ \\
\hline \multirow{2}{*}{ Gender } & Male & & \\
& Female & 334 & $44 \%$ \\
& & 425 & $56 \%$ \\
Race & Malay & & \\
& Chinese & 691 & $91.0 \%$ \\
& India & 6 & $0.8 \%$ \\
& Others & 59 & $7.8 \%$ \\
& & 3 & $0.4 \%$
\end{tabular}




\begin{tabular}{llll} 
Current Living & Home & 671 & $88.4 \%$ \\
& Hostel & 88 & $11.6 \%$ \\
\hline
\end{tabular}

Table 3. Analysis Knowledge of Dangerous Effect of Opiates

\begin{tabular}{|c|c|c|c|c|c|c|c|c|c|}
\hline \multicolumn{10}{|l|}{$\begin{array}{l}\text { Type } \\
\text { of }\end{array}$} \\
\hline Drug & & Number & $\%$ & Number & $\%$ & $\begin{array}{l}\text { Heroine } \\
\text { Number }\end{array}$ & $\%$ & Number & $\%$ \\
\hline \multirow[t]{2}{*}{ Male } & Yes & 104 & $13.70 \%$ & 68 & $9.00 \%$ & 147 & $19.40 \%$ & 56 & $7.40 \%$ \\
\hline & No & 230 & $30.30 \%$ & 266 & $35.00 \%$ & 187 & $24.60 \%$ & 64 & $8.40 \%$ \\
\hline \multirow[t]{2}{*}{ Female } & Yes & 116 & $15.30 \%$ & 84 & $11.10 \%$ & 185 & $24.40 \%$ & 278 & $36.60 \%$ \\
\hline & No & 309 & $40.90 \%$ & 341 & $44.90 \%$ & 240 & $31.60 \%$ & 361 & $47.60 \%$ \\
\hline
\end{tabular}

\section{Discussion}

From the finding, we can conclude that knowledge regarding the dangerous effects of drug abuse is considerably low among both female and male adolescent. Indirectly, they can be said to be at higher risk involved with substance abuse problems.

Because the adolescent still do not know about all the type of drug, Prevention-based programs are necessary to decrease demand through informing adolescent about the relative risks of dependence on various illegal drugs based on present knowledge of these risks. As the drug use usually begins after the age of 12 and rises rapidly until 16 years of age [14].

Hence the preventive drug education should begin in early adolescence and should deter or delay drug use through changes in knowledge, attitude, and behavior [15-19]. Adolescent drug education must meet the needs of those naive to drugs as well as those experiencing initial drug exposure. Education provided in the first group is important in modifying young peoples' responses in drug situations and in the latter group it is most meaningful [16].

Besides that, the more information need to provide primarily through the media, principally the television and hoardings. Therefore media and close contact are primarily responsible for imparting knowledge, whether it be a pro or anti-drug use, and this finding are common anywhere, as is seen in others studies. Six hundred and ninety eight (86.5\%) student claimed they were aware of drug abuse. Oshikoya \& Ali, 2006 founded that the television, radio and billboard advertisement were the students major sources of awareness about drug.

Haddad et al., 2010 reported parents, friends, and teachers also can be a major source of information among adolescents.

\section{Conclusion}

Using the obtained result of this research, knowledge of adolescent toward drug abuse are identified. The organized continuous decision makings and programs can be implemented to raise knowledge and attitude of the students toward drug abuse and to decrease the rate of dependence to drugs. Considering the importance of adolescent acnt role age in forming personal behaviors in the future and the opportunity provided at schools, paying more intentions in teenagers can have a significant role in decreasing drug abuse in this age group and consequently in the society by increasing their knowledge and correcting their attitude toward drug abuse.

The literature surveyed indicates that knowledge of drugs and perceptions of drug prevalence and the harm associated with drug use tend to be mediated by individual experience of drugs, personal acquaintance with drug users, media coverage of drugs and drug use, and social and demographic variables. Attitudes to drugs and drug use may also depend to some extent on social group membership and the attitudes held by the social group as a whole. An association has also been found between gender and perceptions of drug related harm, with women perceiving drug use as far riskier than men. Societal attitudes towards drug users have similarly complex origins, but research indicates they have a tendency to be negative. These negative attitudes exacerbate the sense of alienation felt by drug addicted individuals and discourage them from seeking help for their problem.

Inspite of being aware of the dangerous effects of substance use, adolescents take up this habit. This requires comprehensive prevention and control programs in schools and the community, targeted 
toward adolescents and their parents and other family members. Effective measures are required to encourage shaping the attitude of school children toward selfconfidence and adequacy, as also to prevent risk behavior among adolescents.

\section{Reference}

1. S. Chatterjee, B. Tempalski, E. Pouget, HL. Cooper, CM. Cleland, SR. Friedman, Changes in the Prevalence of Injection Drug Use Among Adolescents and Young Adults in Large U.S. Metropolitan Areas. AIDS and Behavior 15,1570-1578 (2011)

2. CJ. Schwarz, Knowledge and attitude of undergraduate and graduate social work students towards addiction and those who use illegal drugs (California State University, Long Beach, 1997)

3. RA. Gassman, HW. Demone, R. Albilal, Journal of Social Work Education 37, 137-145 (2001)

4. VJ. Giannetti, JD. Sieppert, MJ. Holosko, Journal of Health and Social Policy 15, 45-58 (2002)

5. L. Warburton, D. Callfas, SL. Neubauer, Can Pharm J, 140, 366-75 (2007)

6. O. Prakash, OP. Giri, AK. Mishra, S. Kumar, P. Kulhara, J Mental Health \& Human Behavior 14, 4-79 (2009)

7. D. Tsering, R. Pal, A. Dasgupta, J Pharmacy and Bioallied Sciences 2, 137-40 (2010)

8. B. Happell, B. Carta, J. Pinikahana, Nursing and Health Sciences 4,193-200 (2002)

9. CJ. Heckman, JL. Dykstra, BN. Collins, Health Education Journal 20, 1-17 (2010)

10. A. Bryan, R. Moran, E. Farrell, M. O'Brien, Drug-Related Knowledge, Attitudes and Beliefs in Ireland: Report of a Nation-Wide Survey (Dublin: The Health Research Board, 2000)

11. Agensi Anti Dadah Kebangsaan (Kementerian Dalam Negeri, Malaysia, 2015)

12. S. Galea, A. Nandi, D. Viahoc, The social epidemiologi of substance use. Epidemiologic Review 26, 36-52 (2004)

13. Mohd Najib Abd Ghafar. (1999). Penyelidikan Pendidikan. Skudai, Johor. Penerbit Universiti Teknologi Malaysia.

14. D. White, M. Pitts, Addiction 93,147587(1998)

15. HM. Belcher, HE. Shinitzky, Arch Pediatr Adolesc Med 152, 952-60 (1998)

16. NS. Tobler, T. Lessard, D. Marshall, Effectiveness of school-based drug prevention programs for marijuana use. School PsycholInt 20, 105-37 (1999)

17. DR. Black, NS. Tobler, JP. Sciacca, J School Health 68, 87-93 (1998)

18. N. McBride, Health Educ Res 18, 729-42 (2003)
19. J. Lilja, BU. Wilhelmsen, S. Larsson, D. Hamilton, Subst Use Misuse, 38,1831-63 (2003) 